\title{
THE PREVALENCE OF PERIPHERAL NEUROPATHY IN HEMODIALYSIS PATIENTS AT AL-AZHAR UNIVERSITY HOSPITAL IN NEW DAMIETTA CITY
}

\author{
By
Sherief M. Al-Shazly*, Mohammad Ali Saeed Hassan, El-Sayed Fathi Ali Hamed*, Mohammad Mahmoud Abd El-Aziz Mohammad*
Neurology Department, Faculty of Medicine, Al-Azhar University (Cairo and Damiatta*), Eygpt \\ *Corresponding author: Mohammad Mahmoud AbdElaziz Mohammad, \\ E-mail: drzezo531@gmail.com
}

\begin{abstract}
Background: Chronic kidney disease (CKD) is a worldwide public health problem. There are several etiologies for CKD. It can occur due to either primary kidney disease or as a complication of a multisystemic disorder. Much emphasis has been placed on the increased cardiovascular risk and electrolyte abnormalities that accompany chronic kidney disease. The dreaded neurological complications are usually the uremic encephalopathy or a vascular event that accompanies hypertension.
\end{abstract}

Objectives: To study the prevalence of peripheral neuropathy in uremic patients on hemodialysis and its clinical and neurophysiological characters at Al-Azhar University Hospital in New Damietta.

Patients and Methods: This study was a cross-sectional study. This study was carried out at Hemodialysis Centerat Al-Azhar University Hospital in New Damietta.

Fifty hemodialysis patients were investigated in the Hemodialysis Centerat Al-Azhar University Hospital in New Damietta. All patients were submitted to clinical evaluation by the Michigan Neuropathy Screening Instrument (MNSI), and Electroneuromyography (ENMG), and laboratory investigations.

Results: The results of the study revealed that there was no significant relation between dialysis mode and severity of neuropathy, and there was significant relation between duration of dialysis and neuropathy of the studied cases.

Conclusion: The present study emphasized the high prevalence of peripheral neuropathy in a group of patients with end-stage kidney disease under hemodialysis maintenance treatment. The gold standard exam for diagnosis confirmation was nerve conduction studies. Thus, before undergoing dialysis, it would be recommended to submit all patients with CKD to nerve conduction studies.

Keywords: Dialysis, neuropathy, severity, CKD, case-control, motor, sensory.

\section{INTRODUCTION}

Chronic Kidney Disease (CKD) is a major public health problem in developed and developing countries, leading to decreased quality of life across the globe. It is a well-known fact that patients of
CKD are at increased risk of mortality as well as morbidity due to the myriad complications associated with this disease entity (AbdElHafeez et al., 2018).

Neurological complications, secondary to the uremic state, contribute largely to 
the morbidity and mortality in patients with renal failure. Despite continuous therapeutic advances, many neurological complications of uremia, like uremic encephalopathy, atherosclerosis, neuropathy, and myopathy fail to respond completely to these treatment modalities (Rizzo et al., 2012).

Studies of neuropathy in the end-stage renal disease have demonstrated that 70 $100 \%$ of patients on dialysis experience neuropathic symptoms despite attaining current targets of dialysis adequacy (Aggarwalet al., 2013).

Although the prevalence of severe neuropathy may appear to have decreased to a certain extent, a significant cohort of end-stage renal disease patients still report symptoms which are considered functionally disabling, and even patients who meet accepted guidelines for dialysis adequacy may complain of neuropathic symptoms, Renal transplantation remains the only known cure for uremic neuropathy, with clinical improvement in sensory and, to a lesser extent, motor function occurring within a few days of transplantation (Arun et al., 2009).

The present work aimed to study the prevelance of peripheral neuropathy in uremic patients on hemodyialysis

\section{SUBJECTS AND METHODS}

Permission from The Faculty of Medicine Ethical Committee was obtained, and approval from the institutional review board was taken.

The researcher introduced himself to all participants included in this study and asked them to participate after illustrating the goal of the study.
All selected participants received comprehensive information regarding the objective and the expected benefit of the study. All ethical considerations were taken throughout the whole work. Informed verbal consents from all participants were taken and confidentiality of information was assured.

This study was a cross-sectional study. This study was carried out at the hemodialysis center at Al-Azhar University Hospital in New Damietta (Fifty hemodialysis patients).

\section{Inclusion criteria:}

All patients irrespective of age and sex, and patients with end-stage chronic kidney disease on hemodialysis 4 hours' duration and 3 cycles per week.

\section{Exclusion criteria:}

Patients denying Consent, patients on peritoneal dialysis, patients who had a renal transplant, patient with other known cause of peripheral neuropathy such as hypothyroidism, alcohol, diabetes mellitus, patients on drugs having peripheral neuropathy as established toxicity, malignancy, and vitamin B6 deficiencies.

History: This included Sociodemographic factors, with special emphasis on the cause, onset, duration of kidney disease, duration of hemodialysis, detailed neurological history with particular reference to the presence of risk factors for polyneuropathy and the occurrence of symptoms indicating peripheral neurological damage.

Diagnosis of UN (Uremic Neuropathy): This was investigated by the Michigan Neuropathy Screening Instrument 
questionnaire (MNSI_Q), and physical assessment (Duraisamy and Parthasarathy, 2018).

Neurological examination was done with special emphasis on peripheral nerve examination.

Laboratory investigations were performed for every patient before the electrophysiological examination. The Parameters included $\mathrm{CBC}$, S. creatinine, and fasting blood glucose.

Electrophysiological studies were performed by using Mihonkohden Machine for motor nerve conductions, sensory nerve conduction, late responses, and EMG Protocol.

\section{Statistical analysis:}

Analysis of data was done using the Statistical Package for Social Science version 20 (SPSS Inc., Chicago, IL, USA). Quantitative variables were described in the form of mean and standard deviation, and range. Qualitative variables were described as number and percentage. To compare parametric quantitative variables between two groups, the Student t-test was performed. Qualitative variables were compared using the chi-square (X2) test or Fisher's exact test when frequencies were below five. Pvalue $<0.05$ was considered significant.

\section{RESULTS}

The cause of chronic kidney disease was chronic glomerulonephritis in $38 \%$, chronic interstitial nephritis in $26 \%$, hypertension in $6 \%$, obstructive chronic kidney disease in $10 \%$, congenital in $10 \%$ and others in $10 \%$ (Table $\mathbf{1}$ ).

Table (1) Causes of chronic kidney disease in studied cases

\begin{tabular}{|l|c|c|}
\hline Causes of chronic kidney disease & N & $\%$ \\
\hline Chronic glomerulonephritis & 19 & 38 \\
\hline Chronic interstitial nephritis & 13 & 26 \\
\hline Obstructive chronic kidney disease & 5 & 10 \\
\hline Congenital & 5 & 10 \\
\hline Hypertention & 3 & 6 \\
\hline Others & 5 & 10 \\
\hline
\end{tabular}

The mean Session length per week was $11.7 \pm 1.1$ with range of 8-13 hours, Lowflux was present in $56.0 \%$ and High-flux was in $44 \%$, hemodialysis in $88 \%$ and
Hemodiafiltration in $12 \%$, and demyelination was present in $21 \%$ of cases, axonal in $39.5 \%$ and combined in $39.5 \%$ (Table 2). 
Table (2) Types of neuropathy and dialysis characteristics of the studied cases

\begin{tabular}{|l|c|c|}
\hline Types of Neuropathy & $\mathrm{N}$ & $\%$ \\
\hline Demyelination & 8 & 21.0 \\
Axonal & 15 & 39.5 \\
Combined & 15 & 39.5 \\
\hline \multicolumn{2}{|c|}{ Session length per week (Hours) } \\
\hline Mean \pm SD & \multicolumn{2}{|c|}{$11.7 \pm 1.1$} \\
Range & $\mathrm{N}$ & $\%$ \\
\hline Dialyzer type & 28 & 56.0 \\
\hline Low-flux & 22 & 44.0 \\
High-flux & $\mathrm{N}$ & $\%$ \\
\hline Dialysis mode & 44 & 88.0 \\
\hline Hemodialysis & 6 & 12.0 \\
Hemodiafiltration & & \\
\hline
\end{tabular}

$76 \%$ of cases have ENMG evidence of polyneuropathy, and $36 \%$ have scored MNSI scores between 5-10 out of 10 and $58 \%$ have scored MNSI scores between 3-
5.5 out of 10 and $2 \%$ have scored MNSI scores between 1-2.5 and 4\% not have any point of MNSI scores (Table 3).

Table (3): ENMG evidence of polyneuropathy and MNSI score among studied cases

\begin{tabular}{|l|l|l|l|l|}
\hline Variables & \multicolumn{3}{|l|}{ Present } & Absent \\
\hline \multirow{2}{*}{$\begin{array}{l}\text { ENMG evidence } \\
\text { of polyneuropathy }\end{array}$} & $\mathrm{N}$ & $\%$ & $\mathrm{~N}$ & $\%$ \\
\cline { 2 - 5 } & 38 & 76 & 12 & 24 \\
\hline Cases: & $\mathrm{N}$ & $\%$ & \\
\hline MNSI score: & 18 & 36.0 & \\
\hline $\mathbf{5 - 1 0}$ & 29 & 58.0 & \\
$\mathbf{3 - 5 . 5}$ & 1 & 2.0 & \\
$\mathbf{1 - 2 . 5}$ & 2 & 4.0 & \\
No point & 2 &
\end{tabular}

There was a significant relation between the duration of dialysis and neuropathy of the studied cases (Table 4).

Table (4): Relation between duration of dialysis and neuropathy of the studied cases

\begin{tabular}{|c|c|c|c|}
\hline $\begin{array}{c}\text { Duration } \\
\text { of dialysis }\end{array}$ & $\begin{array}{c}\text { With neuropathy } \\
\mathbf{N = 3 8}\end{array}$ & $\begin{array}{c}\text { Without neuropathy } \\
\mathbf{N = 1 2}\end{array}$ & P-value \\
\hline Mean \pm SD & $5.11 \pm 1.75$ & $3.01 \pm 0.95$ & $\begin{array}{c}<\mathbf{0 . 0 0 1} \\
\text { (S) }\end{array}$ \\
\hline
\end{tabular}

There was no significant relation between Dialysis mode and severity of neuropathy (Table 5). 
Table (5) Relation between Dialysis mode and severity of neuropathy

\begin{tabular}{|c|c|c|c|c|c|c|c|}
\hline $\begin{array}{l}\text { Dialysis } \\
\text { mode }\end{array}$ & \multicolumn{2}{|c|}{$\begin{array}{c}\text { Pevere neuropathy } \\
\mathrm{N}=18\end{array}$} & \multicolumn{2}{c|}{$\begin{array}{c}\text { Moderate } \\
\mathrm{N}=10\end{array}$} & \multicolumn{2}{c|}{$\begin{array}{c}\text { Mild } \\
\mathrm{N}=10\end{array}$} & P-value \\
\hline & NO. & $\%$ & NO. & $\%$ & NO. & $\%$ & \\
\hline $\begin{array}{c}\text { Hemodialysis } \\
\text { Hemodiafiltration }\end{array}$ & 16 & 88.9 & 8 & 80.0 & 9 & 90.0 & 0.453 \\
\hline
\end{tabular}

In patients with neuropathy there was a predominant decrease in CMAP conduction velocity, and prolonged distal amplitudes with relatively decreased latency (Table 6).

Table (6): Motor nerve conduction studies in the study

\begin{tabular}{|c|c|c|c|c|c|c|}
\hline \multirow[t]{2}{*}{$\begin{array}{l}\text { Parameters } \\
\text { Variables } \\
\end{array}$} & \multicolumn{2}{|c|}{$\begin{array}{l}\text { Decrease in } \\
\text { CMAP } \\
\text { amplitude }\end{array}$} & \multicolumn{2}{|c|}{$\begin{array}{c}\text { Decrease } \\
\text { Conduction } \\
\text { velocity }\end{array}$} & \multicolumn{2}{|c|}{$\begin{array}{l}\text { Prolonged distal } \\
\text { latency }\end{array}$} \\
\hline & No & $\%$ & No & $\%$ & No & $\%$ \\
\hline \multicolumn{7}{|l|}{ Peroneal } \\
\hline & 34 & 68.0 & 33 & 66.0 & 21 & 42.0 \\
\hline \multicolumn{7}{|l|}{ Tibial } \\
\hline & 33 & 66.0 & 30 & 60.0 & 19 & 38.0 \\
\hline \multicolumn{7}{|l|}{ Ulnar } \\
\hline & 15 & 30.0 & 15 & $\overline{30.0}$ & 2 & 10.0 \\
\hline \multicolumn{7}{|l|}{ Median } \\
\hline & 14 & 28.0 & 14 & 28.0 & 2 & 10.0 \\
\hline
\end{tabular}

Patients with neuropathy were showed decreased SNAP amplitudes with relatively decreased conduction velocity (Table 7).

Table (7): Sensory nerve conduction studies in the study.

\begin{tabular}{|l|l|l|l|l|}
\hline $\begin{array}{l}\text { Parameters } \\
\text { Variables }\end{array}$ & $\begin{array}{l}\text { Decrease } \\
\text { amplitude }\end{array}$ & SNAP & \multicolumn{2}{l|}{ Decreased conduction velocity } \\
\hline \multicolumn{5}{|l|}{} \\
\hline No & $\%$ & No & $\%$ \\
\hline & 38 & 76.0 & 35 & 70.0 \\
\hline Median & 20 & 40.0 & 22 & 44.0 \\
\hline \multicolumn{7}{|l|}{} \\
\hline Ulnar & 17 & 34.0 & 20 & 40.0 \\
\hline
\end{tabular}

$2.6 \%$ of patients have motor weakness, and $50 \%$ have sensory symptoms, and $44.7 \%$ have autonomic symptoms, No patient have wasting of limbs, and $78.9 \%$ have absent ankle jerk, and $31.6 \%$ have impaired pain and temperature, $44.7 \%$ have impaired vibration and joint position sense (Table 8). 
SHERIEF M. AL-SHAZLY et al.,

Table (8): Symptoms and signs in Cases in the study

\begin{tabular}{|l|c|c|}
\hline Variables & \multicolumn{2}{|c|}{ Cases } \\
\hline Motor weakness : & 1 & \% \\
\hline \multicolumn{2}{|c|}{19} & 50.0 \\
\hline Sensory symptoms : & 17 & 44.7 \\
\hline \multicolumn{2}{|c|}{10} \\
\hline Autonomic symptoms: & 30 & 78.9 \\
\hline Wasting of limbs: & 12 & 31.6 \\
\hline \multicolumn{2}{|c|}{17} & 44.7 \\
\hline Absent ankle jerk: & 17 \\
\hline Impaired pain and temperature : \\
\hline Impaired vibration and joint position sense : \\
\hline \multicolumn{2}{|c|}{} \\
\hline
\end{tabular}

\section{DISCUSSION}

The present study showed that the cause of CKD was CGN in $38 \%$, CIN in $26 \%$, hypertension in $6 \%$, obstructive CKD in $10 \%$, congenital in $10 \%$, and others in $10 \%$.Our results were supported by the study of Macárioet al. (2011) as they reported that in Portugal the main etiologies for CKD in the patients under hemodialysis treatment are DM (33.6\%), undetermined $(20.7 \%)$, and arterial hypertension $(15.5 \%)$.

The current study showed that demyelination was present in $21 \%$ of cases, axonal in $39.5 \%$ and combined in 39.5. A patient has motor weakness $2.6 \%$, and $50 \%$ have sensory symptoms, and $44.7 \%$ have autonomic symptoms, and $0 \%$ have wasting of limbs, and $78.9 \%$ have absent ankle jerk, and 31.6\% have impaired pain and temperature, and 44.7 $\%$ have impaired vibration and joint position sense. Our results were supported by the study of Kolli et al. (2018) who reported that positive sensory symptoms were seen in $48.5 \%$, while negative sensory symptoms were seen in $38.5 \%$. Autonomic symptoms were seen in $8.5 \%$. $80.5 \%$ had absent ankle jerk. Impaired pain and temperature sensation were noted in $30.5 \%$, while impaired vibration and joint position sense was noted in $43 \%$. Motor weakness was noted in $3 \%$ of patients. According to Anbarasu and Prathiba (2018) $71.6 \%$ of patients were diagnosed as having clinical peripheral neuropathy, and $28.33 \%$ had not satisfied the diagnosis of clinical peripheral neuropathy.

Furthermore, Santos (2012) observed that all the patients with motor symptoms also had sensory symptoms, but not all the patients with sensory symptoms had motor symptoms.

As regard MNSI scores, 36\% have scored MNSI scores between 5-10 out of 10 , and $58 \%$ have scored MNSI scores between 3-5.5 out of 10 , and $2 \%$ have scored MNSI scores between 1-2.5, and $4 \%$ did not have any point of MNSI scores Mambelli, et al. (2012) concluded the study by saying that MNSI could 
represent a valid and simple clinicalinstrumental screening test for the early diagnosis of UN because of an early therapeutic approach. The course of neuropathy is variable in patients undergoing hemodialysis. Routine hemodialysis has found not to improve neuropathy in patients with CKD despite the decrease in urea and creatinine levels, this was emphasized by Borire et al. (2017).

As regard hemodialysis characteristics, the mean session length per week was $11.7 \pm 1.1$ with a range of 8-13 hours. Low-flux was present in $56.0 \%$ and highflux was in $44 \%$. Hemodialysis was in 88 $\%$ and hemodiafiltration was at $12 \%$. Our results showed that $76 \%$ of cases have ENMG evidence of polyneuropathy. $58 \%$ of them had 3-5.5 of MNSI score. Our results are supported by the study of Anbarasu and Prathiba (2018) as they reported that the smallest MNSI score obtained in the study population was 2 and the largest score was 7 with a mean score of 2.580 with a standard deviation of 2.069 .

The current study showed that there was no significant relation between demographic data and neuropathy. Anbarasu and Prathiba (2018) reported that males were significantly more affected by peripheral neuropathy when compared to females. Concerning age, in their study, it was found that patients aged $\geq 60$ years were predominantly affected by uremic neuropathy which was statistically very significant.

Our results showed that there was a significant relation between neuropathy and urea level, while there was no significant relation between other renal functions and neuropathy. There was no significant relation between neuropathy and the etiology of CKD in the study of the studied cases. There was a significant relation between the duration of hemodialysis and neuropathy of the studied cases.

In the present study, there was no significant relation between hemodialysis mode and severity of neuropathy. There was a significant relation between renal function and neuropathy severity of the studied cases. In patients with neuropathy, there were a predominant decrease in compound motor action potential (CMAP) amplitudes with relatively decreased conduction velocity, and prolonged distal latency. Abnormalities were found in the peak latency, sensory nerve action potential (SNAP) amplitude and conduction velocity (CV) of the sural, median, ulnar nerves. In patients with neuropathy, SNAP amplitudes decreased with relatively decreased conduction velocity. Aggarwal et al. (2013) showed that mean nerve conduction velocities $(\mathrm{m} / \mathrm{sec})$, which were almost similar to this study. Tilki et al. (2009) reported that the prevalence of uremic neuropathy is $60 \%$ $100 \%$ of patients on hemodialysis. Neuropathy generally only develops at glomerular filtration rates of less than 12 $\mathrm{mL} / \mathrm{min} / 1.73 \mathrm{~m} 2$. In stage $\mathrm{V}$ CKD (on $\mathrm{HD}$ ), the prevalence of clinical uremic peripheral neuropathy was $71.6 \%$ which was clinically and statistically significant.

\section{CONCLUSION}

The present study emphasized the high prevalence of peripheral neuropathy in a group of patients with end-stage kidney disease under hemodialysis maintenance treatment. Despite the short period, the 
study was conducted and, consequently, small sample size, the obtained results allowed us to highlights the huge importance of having neurologists and nephrologists as well as other specialists working all together to better diagnose and manage neurological complications of end-stage kidney disease in those patients. The standard exam for diagnosis confirmation is nerve conduction studies. Thus, before undergoing hemodialysis, it would be recommended to submit all patients with CKD to nerve conduction studies.

\section{REFERENCES}

1. Aggarwal HK, Sood S, Jain D, Kaverappa $v$ and Yadav S. (2013): Evaluation of spectrum of peripheral neuropathy in predialysis patients with chronic kidney disease. Renal failure, 35:1-7.

2. Anbarasu D., and Prathiba P. (2018): Study on prevalence of peripheral neuropathy among patients on hemodialysis.IAIM, 5(10): 73-80.

3. AbdElHafeez S, Bolignano D, 'Arrigo G, Dounousi E,Tripepi $G$, and Zoccali C. (2018): Prevalence and burden of chronic kidney disease among the general population and high-risk groups in Africa: a systematic review BMJ Open, 8:e015069.

4. Kolli, S. (2018): A Clinical and Electrophysiological Study of Peripheral Neuropathies in Predialysis and Dialysis Patients: Our Experience from South India. Journal of The Association of Physicians of India, 66(6):31-37.

5. Macário F, Filipe R, Carvalho MJ, Galvão A, Lopes JA, Amoedo M. (2011): Diálise Domiciliária. SPNews - Sociedade Portuguesa de Neurologia, VII (24):1-20.

6. Mambelli E, Barrella M, Facchini MG, Mancini E, Sicuso C, Bainotti S, Formica $M$ and Santoro A. (2012): The prevalence of peripheral neuropathy in hemodialysis patients. Clinical Nephrology, 77(6): 468-75.

7. Rizzo MA, Frediani F, Granata A, Ravasi B, Cusi D, and Gallieni M. (2012): Neurological complications of hemodialysis: J Neph., 25(02): 170-182.

8. Santos, A. O. P. (2012): Peripheral neuropathy in patients in haemodialysis treatment Doctoral dissertation, Universidade da Beira Interior.

9. Tilki HE, Akpolat T, Coşkun M, and Stålberg E. (2009): Clinical and electrophysiologic findings in dialysis patients. Journal of Electromyography and Kinesiology, 19(3): 500-8. 
انتشار اعتلال الاعصاب الطرفية عند مرضى غسيل الكلى الإي

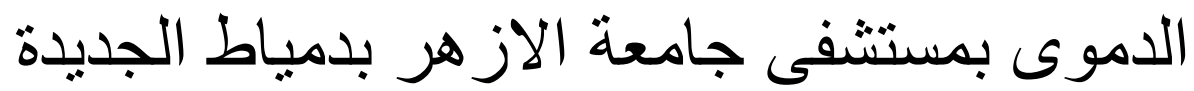
شريف محمود الثاذلى*، محمد على سعيد حسن، السيد فتحى على حامد*، محمد الأل

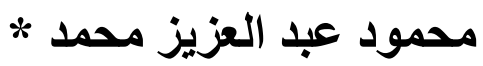

قسم طب المخ والاعصاب بكلية الطب جامعة الازهر، (القاهرة و دمياط*)، مصر

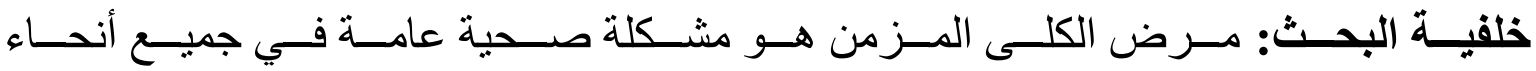

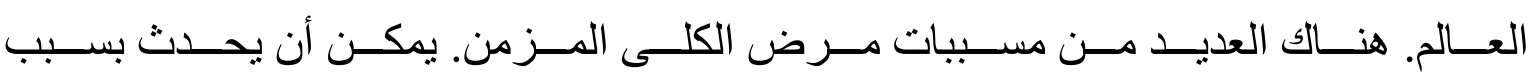

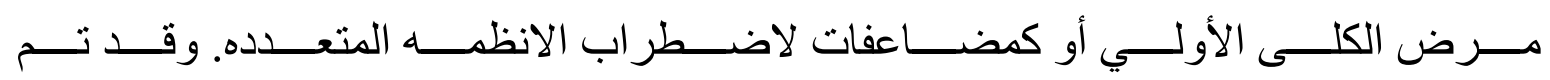

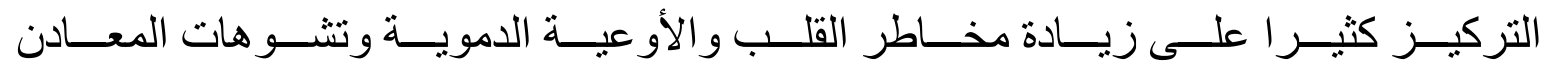

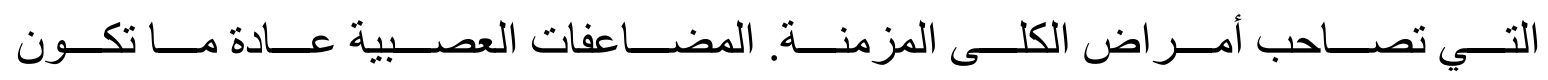

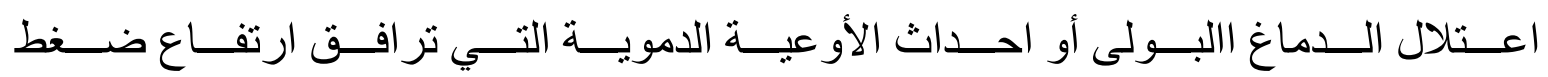

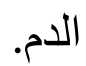

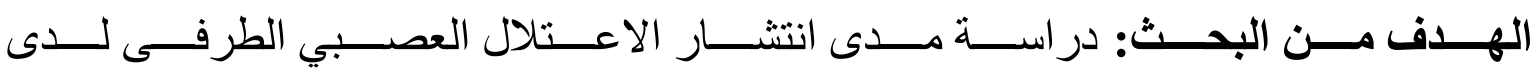

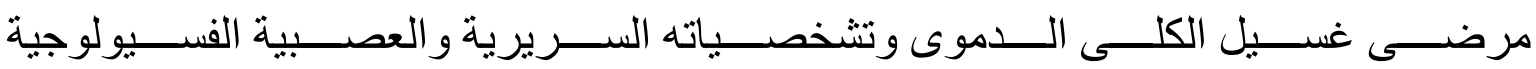
في مستشفى جامعة الأزهر بدمياط الجديدة.

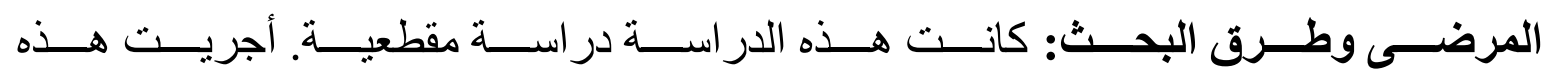

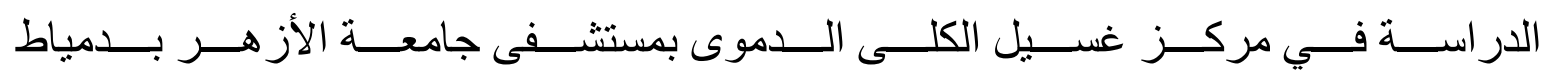

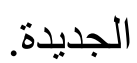

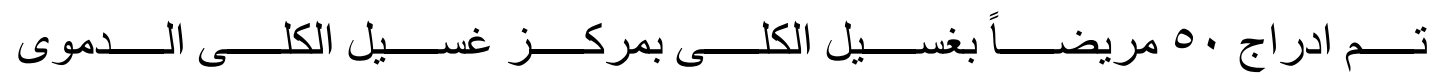

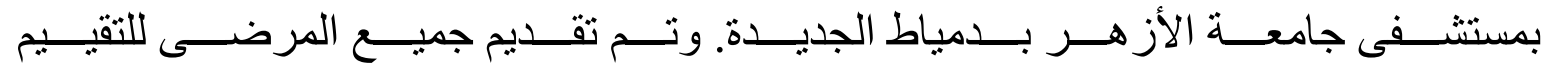

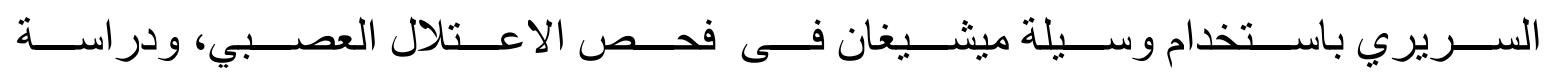
فسيولوجيا الاعصاب، و التحقيقات المختبرية. 


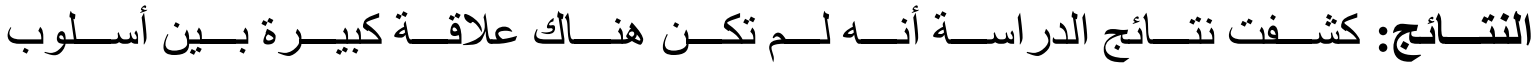

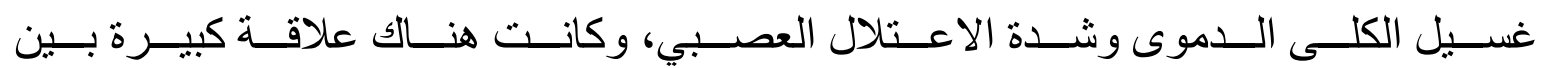
مدة غسيل الكلى والاعتلال العصبي للحالات المدروسة.

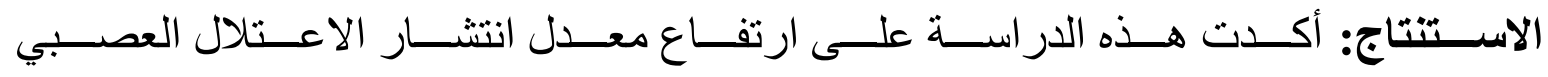

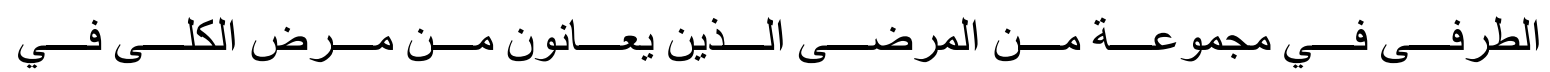

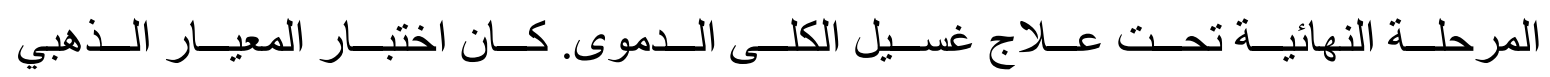

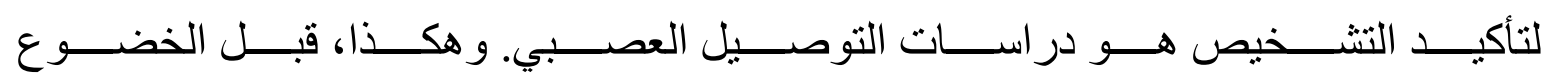

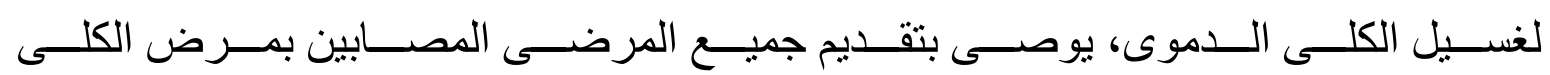
المزمن إلى در اسات التوصبل العصبي. 